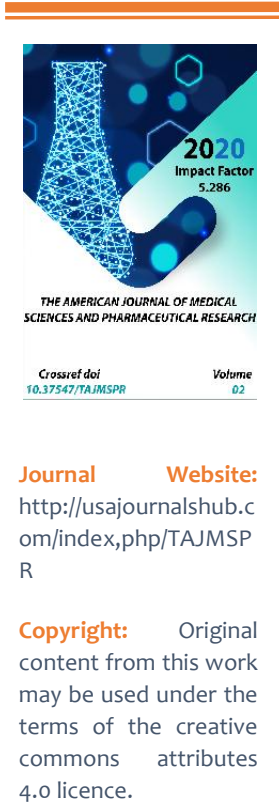

\title{
Assessment Of Changes In The Condition Of Periodontal Tissues In Workers Exposed To Exposure To Epoxy Resin
}

\author{
Rizayev Jasur Alimdjanovich \\ Rector Of Samarkand State Medical Institutedoctor Of Medical Sciences, Professor, \\ Uzbekistan \\ Nazarova Nodira Sharipovna \\ Dentistry Course Samarkand State Medical Institutesamarkand Doctor Of Philosophy In \\ Medical Sciences, Associate Professor, Uzbekistan
}

\section{ABSTRACT}

The purpose of this review is to analyze studies evaluating the harmful effects of epoxy resins on periodontal tissue in workers at the Fiberglass plant in comparison with the control group of those surveyed.

With the progressive growth of the chemical industry and the extensive chemicalization of multiple areas and branches of the national economy, the regular introduction into production of various chemical compounds that have irritating, toxic, sensitizing, carcinogenic properties on the body, it becomes more and more urgent and very important to study them in more detail.

\section{KEYWORDS}

Condition of periodontal tissues, epoxy resin, unfavorable production factors, fiberglass, chemical compounds.

\section{INTRODUCTION}

Epoxy resins were first used on a commercial basis in 1946 and are currently used in a wide variety of sectors of the national economy, including shipbuilding, chemical, automobile, road, construction, aviation, furniture, agriculture and household use. [2, 3].

The properties of epoxy resins are controlled by modification and are the most common additives used to improve physical and 
mechanical properties such as modulus of elasticity and strength. One of the most important uses of epoxy resins is in protective coatings, which account for almost $69 \%$ of total consumption and can also be used for decorative purposes in some products.

The study of dental morbidity in persons exposed to harmful industrial chemical factors shows that in most cases there is a general trend in the development of pathological processes in the oral cavity. Dental caries and its complications, inflammatory diseases, as well as periodontal damage have an etiological relationship with a violation of the microbiocenosis of the oral cavity. The constant influence of chemical compounds in low concentrations in the air on the oral mucosa can contribute to a change in the composition of saliva, the structure of the microbiocenosis, which ultimately leads to a secondary deterioration in the hygienic state of the oral cavity $[4,6]$.

The aim of this study was to study changes in the state of periodontal tissues in workers exposed to epoxy resin.

\section{MATERIAL AND RESEARCH METHODS}

To assess the effect of epoxy resin on the functional state of the organs and tissues of the oral cavity of workers, all patients were divided into groups that were homogeneous in age and work experience.

1 group of patients - with chronic periodontitis among workers of the Fiberglass plant - 130 patients.

Group 2 - patients with clinically healthy periodontal tissues, with local risk factors, such as unsatisfactory oral hygiene, overhanging edges of the filling, etc. - 120 patients.

The data received were subjected to statistical processing using the Microsoft Excel application package. The significance of the difference in parameters was determined by the Student's test.

\section{RESULTS AND DISCUSSION}

The problem of treatment and prevention of diseases of the oral cavity in persons whose production activity is associated with the action of professional factors has not lost its relevance.

According to the data of previous studies, it was found that the production and professional factors at the enterprise are fiberglass dust, chemicals that make up the lubricant and its decay products, an unfavorable microclimate at workplaces, as well as industrial noise $(7,8)$.

Epoxy resin is a product of the chemical industry, capable of forming crosslinked polymers under the influence of hardeners. Epoxy resin is widely used in various fields: for the manufacture of various adhesives, plastics, and even carbon fiber for aircraft components. In addition, the resin is used in various hulls such as boats and indoor waterproofing.

Also, in recent years, epoxy resin has become very popular in furniture production due to its transparency and strength: it is used to create designer tables, chairs, countertops and even wooden decorations, such as rings. To give additional aesthetics, resin in joinery is most often tinted, sometimes a phosphor is added for the effect of glow in the dark, often an object is placed inside the resin layer, for example, a beautiful stone. All in all, epoxy in joinery opens up almost limitless possibilities for creativity. Working with the resin is very simple: it is mixed with a hardener in a ratio of 10: 1 to 5: 1 (depending on the type of hardener), mixed, poured into the desired mold, and the resin is completely hardened 
after 24 hours. Used for its hardening (hardeners) are hazardous to health.

The main ways of getting the resin and the reagents used with it into the human body are through the skin, the oral cavity and the inhalation of vapors and dust. When hardeners come into contact with the skin, such problems often arise, since among them there are irritants that cause toxic eczema, and sensitizers that lead to the development of allergic contact dermatitis. Polyamides (most modern hardeners are cycloaliphatic polyamides) are less harmful to the skin than amines, but more often cause allergic reactions. Inhalation of small amounts of vapors of hardeners, even amine ones, which are considered more aggressive, usually do not cause poisoning, but they all have an unpleasant odor and can cause irritation of the upper respiratory tract, oral mucosa and periodontal tissues.

Chemical compounds as toxic dust can settle in the form of plaque in the area of the necks of the teeth, or through the damaged mucous membrane for faster penetration and absorption, which causes serious consequences in the form of periodontitis, stomatitis. The damage that chemicals cause to certain organs depends on the amount (dose) of the chemical absorbed by the body. Inflammatory diseases, as well as damage to the periodontal, have an etiological relationship with a violation of the microbiocenosis of the oral cavity.

The constant influence of chemical compounds in low concentrations in the air and on the mucous membrane of the oral cavity can contribute to a change in the composition of saliva, the structure of the microbiocenosis, which ultimately leads to a secondary deterioration in the hygienic state of the oral cavity.
The high prevalence, propensity for progression and multifaceted impact, both on the dentition and the body as a whole, as well as ambiguous approaches to treatment, make it possible to classify periodontal diseases among the most problematic nosologies in modern medicine.

The inconspicuous and asymptomatic course of the initial changes in the periodontal tissues often leads to the fact that patients with an already developed stage of the disease seek help [2,3].

Despite the obvious progress in the study of the etiology and pathogenesis of periodontal diseases, the improvement of diagnostics and treatment occupy one of the leading places among dental diseases [4,6].

To date, a huge number of schemes and methods for the treatment of chronic periodontitis have been proposed. Despite this, there is no decrease in the incidence of periodontal tissues. In addition, there is an insufficient level of professional training of dentists on the issues of periodontology, the unsatisfactory technical and material provision of medical institutions affects, there are no clear criteria for assessing the effectiveness of the treatment $[1,7]$.

Recent studies conducted by foreign authors $(4,7)$ show a decrease in interest in preventive measures in patients with periodontal diseases. According to Yu.A. Fedorov, insufficient attention to preventive measures in dental practice can lead not only to pathology of the oral cavity organs, but also to the emergence of general somatic diseases. Evaluating these positions, it becomes clear the need for new approaches in the organization of this type of activity, the development and planning of individual measures in order to prevent the development of dental pathology and improve the effectiveness of therapeutic 
manipulations, highlight the priority areas of primary and secondary prevention of inflammatory periodontal diseases in patients exposed to epoxy resin.

\section{REFERENCES}

1. Abdazimov A.D. Prevention and treatment of dental diseases in workers exposed to the combined effects of polymetallic dust and toxic substances: Dis. Dr. med. nauk. - L., 1989. -347 p.

2. Artamonova, V. G. Occupational diseases/ V. G. Artamonova, N. A. Mukhin - 4th ed. pererab. and add. - M.: Medicine, 2004. $480 \mathrm{p}$.

3. Belyaeva, O. V. Influence of complex therapy on indicators local immunity of periodontitis patients / O. V. Belyaeva, N. N. Kevorkov / / cytokines and inflammation. - 2002. - Vol. 2, No. 4. - Pp. 48-54.

4. Gorbacheva, I. A. Complex approaches to the treatment of patients with combined diseases of internal organs and inflammatory periodontal lesions: autoref. dis. ... doctor of medical Sciences: 14.00.05, 14.00.21 Gorbacheva I. A.-St. Petersburg, 2004. - 42 p.

5. grudyanov, A. I. Etiology and pathogenesis of inflammatory diseases periodonta / A. I. grudyanov, E. V. Fomenko. - M.: Medical news Agency, 2010. - 96 p.

6. Dunyazina, T. M. the Concept of peroxidelysosomal mechanisms in development of periodontal diseases / T. M. Dunyazina // New in dentistry.- 2008. - № 1. - P. 8-12.

7. Zaripova, E. M. Improvement of treatment and prevention works of the dentist of the medical unit of the river shipping company / E. M. Zaripova, E. N.
Mingazova, A. K. Iordanishvili // Periodontics. - 2009. - № 1. - P. 57-59.

8. Kuchumova, Ed. Features of the microcirculation of the periodontal and dental pulp / by E. D. Kuchumov, T. B. Tkachenko // Methods of investigation of microcirculation in the clinic: Mat. scientific and practical Conf. - St. Petersburg, 2001, Pp. 33-36. 